\title{
Tratamiento de la cistitis hemorrágica por ciclofosfamida. Revisión de la literatura a propósito de un caso
}

\author{
P. Serrano Frago, C. Allepuz Losa, P. Gil Martínez, M. Allué López, E. Mallén Mateo, \\ C. Sancho Serrano, L.A. Rioja Sanz
}

Servicio de Urología. Hospital Universiario Miguel Servet. Zaragoza.

Actas Urol Esp 2005; 29 (2): 230-233

\section{RESUMEN}

TRATAMIENTO DE LA CISTITIS HEMORRÁGICA POR CICLOFOSFAMIDA. REVISIÓN DE LA LITERATURA A PROPÓSITO DE UN CASO

Existen situaciones límites en la práctica clínica de hematurias rebeldes a tratamiento, no muy frecuentes hoy en día afortunadamente, en la que por procesos incluso benignos corre serio riesgo la vida del paciente y se plantean actuaciones como la cistectomia.

Es nuestro deseo hacer una revisión de las diversas opciones terapéuticas que existen ante una hematuria intensa que no cede con irrigación continua de suero salino. Recientemente se ha precisado el uso de diferentes técnicas en un paciente joven, que tras administración de ciclofosfamida se controlo la hematuria recurrente e intensa mediante irrigación intravesical de alumina, evitando así una cirugía tan agresiva y con tantas secuelas como la cistectomía.

Palabras clave: Hematuria. Ciclofosfamida. Alumina.

\section{ABSTRACT}

\section{TREATMENT OF HEMORRHAGIC CYSTITIS SECONDARY TO CYCLOPHOSPHAMIDE. LITERATURE REVIEW WITH REGARD TO A CASE}

There are extreme situations in the clinical treatment of intractable hematuria (fortunately not a common disease nowadays), in which even benign process may represent a serious risk to the life of the patient and where certain aggressive procedures like cystectomy have to be considered.

Our objective in this paper is to review the different existing therapeutic alternatives for the treatment of an intense type of hematuria which does not yield to continuous saline serum irrigation. This study is partly based on a recent real clinical case in which, after the administration of cyclophosphamide to a young patient with recurrent and intense hematuria, the excretion was controlled through intravesical alum irrigation of thus avoiding cystectomy, a very aggressive surgical procedure with many after-effects.

Keywords: Cyclophosphaide. Haematuria. Alum irrigation.

L os casos de cistitis hemorrágica incontrolable con irrigación continua de suero o electrocoagulación no son muy frecuentes en nuestro medio, siendo las etiologías más frecuentes la iatrógena por quimioterápicos o radioterapia y los tumores vesicales infiltrantes.

En algunas ocasiones, nos conducen a una seria reflexión acerca de la actuación por la juventud del paciente y del proceso benigno por el que se administró el tratamiento causante de la hematuria. Debido a ésto y a la existencia de diversos tratamientos para la hematuria severa y la necesidad de decidir la más adecuada, según el contexto del caso clínico por no existir un tratamiento de elección, nos ha llevado a revisar las distintas opciones descritas en la literatura.

\section{CASO CLÍNICO}

Varón de 36 años diagnosticado a los 23 de granulomatosis de Wegener con mala respuesta 
al tratamiento de elección con corticoides, sin control de la enfermedad a pesar de instaurar altas dosis de ciclofosfamida. Presenta epistaxis y afectación a nivel de diversos pares craneales, sobre todo del óptico, que le produce ceguera derecha e intensas cefaleas. Como antecedentes urológicos presenta episodios autolimitados de hematuria macroscópica siendo uno de mayor intensidad hace 4 años que requirió hospitalización con transfusión sanguínea y revisión endoscópica. Se descarta una posible neoformación vesical sospechada mediante cistoscopia, confirmándose mediante biopsia el cuadro de cistitis hemorrágica por ciclofosfamida.

El motivo de consulta en urgencias se debe a presentar hematuria macroscópica con dificultad en la micción y con afectación del estado general. Presenta globo vesical con vejiga coagulada que precisa evacuación de coágulos y colocación de sistema lavador. Tras una estabilización inicial, por persistencia del sangrado que provoca anemia aguda con repercusión general e hipotensión, así como nuevos episodios de vejiga coagulada se llevan a cabo cuatro revisiones endoscópicas bajo raquianestesia con extracción de abundantes coágulos. En todas las ocasiones se evidencia una mucosa vesical denudada y sangrante en la que la electrocoagulación de algunas zonas difusas no es efectiva (Fig. 1), siendo preciso medidas de mantenimiento con transfusiones sanguíneas en diversos momentos, antifibrinolíticos y vitamina $\mathrm{C}$.

Ante las múltiples necesidades de revisión quirúrgica y repercusión del estado general por

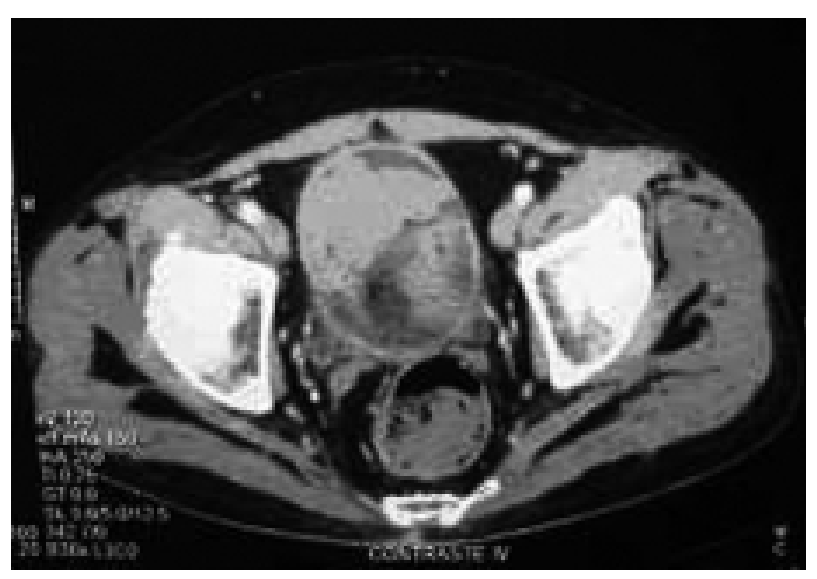

FIGURA 1 anemia, se realiza embolización arterial con partículas plásticas de las arterias vesicales inferiores y grandes ramas anteriores de la vejiga, bilateralmente y en dos ocasiones. Posteriormente a la última evacuación de coágulos se lleva a cabo la última posibilidad de embolización, mediante espirales metálicas de ambas hipogástricas.

Dada la mala evolución y no respuesta a tratamientos llevados a cabo se decide la administración de sulfato potásico de alúmina diluido al $1 \%$ administrado intravesicalmente a un ritmo de 3 a $5 \mathrm{~mL} / \mathrm{min}$. y aumentando hasta un máximo de $10 \mathrm{~mL} / \mathrm{min}$. cuando no cede la hematuria. Se mantuvo durante dos dias después de 6 horas tras el cese de la misma y siempre bajo estricto control clínico (nivel de conciencia, orientación, alerta...) para poder detectar efectos secundarios como la encefalopatía por aluminio y control de aluminio sérico para no exceder niveles tóxicos. Se llevó a cabo la retirada de la sonda tras varios días de rehabilitación vesical con pinzamientos de la misma.

Durante este proceso se fue controlando ecográficamente una mínima dilatación renal bilateral que apareció de forma progresiva tras las diversas embolizaciones pero que no llegó a dañar la función renal, creatinina: $1,1 \mathrm{mg} / \mathrm{dl}$.

El tratamiento debido a su enfermedad de base con ciclofosfamida fue suspendido desde el ingreso del paciente y se administran corticoides e inmunoglobulinas intravenosas bajo control del servicio de medicina interna.

El paciente fue dado de alta tras dos meses de hospitalización con una frecuencia miccional cada 45 minutos a una hora aproximadamente, con leves molestias y con orina clara.

El control en consultas hasta el día de hoy ha sido favorable, sin nuevos episodios de hematurias, con micción confortable y frecuencia miccional cada hora y media. Existe preservación de la función renal y control urográfico que señala la estabilización de la dilatación bilateral del tracto urinario superior (Fig. 2).

\section{DISCUSION}

La hematuria severa puede presentar un serio problema de salud cuando no responde a irrigación mediante sonda vesical tres vías o a electro- 


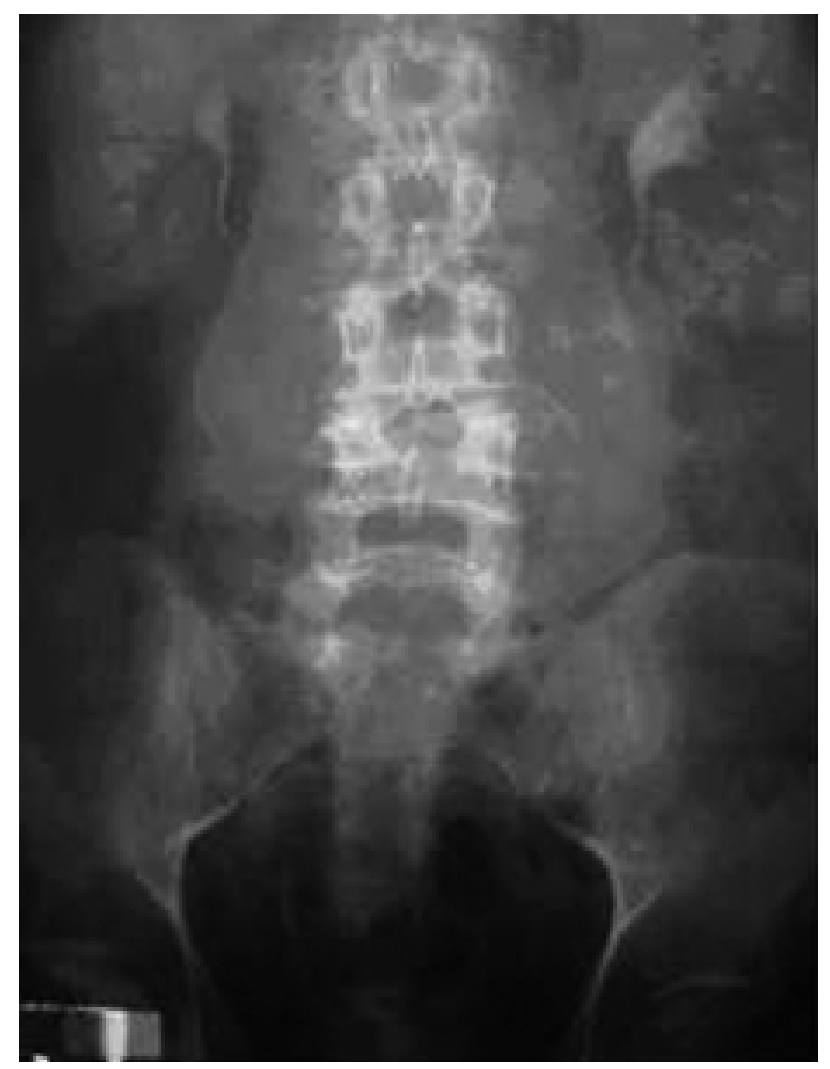

FIGURA 2

fulguración, agravándose la dificultad de la decisión cuando se trata de un paciente joven en el que se evita llegar a la cistectomía. Se han planteado diversos tratamientos como irrigación con prostaglandinas, con alúmina, formol intravesical, ácido aminocaproico, estrógenos orales, pentoxifilina oral, embolización de arterias vesicales, cámara hiperbárica y presión hidrostática (maniobra de Helsteim).

El tratamiento con prostaglandinas se basa en el beneficio que las mismas aportan en la regeneración de la mucosa vesical, siendo pocos sus efectos secundarios y no precisando anestesia, pero de difícil obtención en España, alto coste y vigilancia y pocos resultados descritos ${ }^{1}$

La irrigación con alúmina puede hacerse mediante protocolos diferentes, como $50 \mathrm{~g}$ de alúmina disuelta en 5 litros de agua estéril e irrigarla a un ritmo de $250-300 \mathrm{ml} / \mathrm{h}^{2}$. Otro, con una solución de alúmina al $1 \%$ con irrigación vesical continua comenzando de 3 a $5 \mathrm{ml} / \mathrm{min}$., y aumentando hasta un máximo de $10 \mathrm{ml} / \mathrm{min} \mathrm{si}$ persiste la hematuria o se obstruye la salida por coágulos. Se mantiene la irrigación hasta $6 \mathrm{~h}$ después del cese de la hematuria.
La irrigación con alúmina suele ser bien tolerada y no presenta problemas de toxicidad como son en la clínica: confusión, letargo, acidosis metabólica que obligarían a suspender el tratamiento ${ }^{3}$.

El tratamiento mediante formol intravesical produce precipitación y necrosis de la mucosa, siendo necesario la utilización de anestesia y produciendo importantes efectos secundarios como vejiga retráctil, reflujo ureteral o rotura vesical por lo que se aconseja su utilización si fallan otros tratamientos más conservadores ${ }^{4,5}$

El uso de la irrigación con ácido aminocaproico se basa en su acción antifibrinolítica inhibiendo la activación del plasminógeno, suceden pocos efectos secundarios sistémicos si se administra intravesicalmente, no se conocen las tasas de recidivas cuando responde a este método ${ }^{6}$

El mecanismo de acción de los estrógenos conjugados orales en el tratamiento de la hematuria incoercible se desconoce, pero sí sus efectos secundarios cardiovasculares ${ }^{7}$.

La Pentoxifilina se administraría para oxigenar la mucosa vesical gracias a la disminución de la viscosidad de la sangre y mayor facilidad de circulación periférica, estando contraindicada en pacientes con episodios hemorrágicos cerebrales o retinianos previos ${ }^{8}$.

$\mathrm{El}$ control de la hematuria mediante embolización de las arterias vesicales con diversos materiales biocompatibles se puede realizar mediante anestesia local, con las complicaciones que surgirían de la embolización iatrógena de arterias no deseadas; presentando un $92 \%$ de éxito en una revisión de estudios publicados ${ }^{9}$.

La administración de oxígeno a 2-2,5 atm. Durante 90 a 120 min 5 veces a la semana hasta 40-60 sesiones, puede ser un tratamiento en aquellos centros que posean cámara hiperbárica, teniendo en cuenta la toxicidad del oxígeno y la contraindicación en pacientes con infecciones víricas por riesgo de producir viremia ${ }^{10}$.

La administración de presión hidrostática requiere raquianestesia y se realiza mediante el llenado de un globo intravesical hasta niveles por encima de la presión sanguínea sistólica según Helmstein mantenido durante 6-7 h. El mayor riesgo de esta maniobra es la ruptura vesical $^{11,12}$. 
Así, existen diversos procedimientos para el control de la hematuria intratable previos a la actitud quirúrgica de la cistectomía sin ser ninguno de ellos de elección y debiendo de aplicarlo según los factores de riesgo del paciente, de menor a mayor agresividad y considerando el riesgo-beneficio de aplicarlo en cada momento.

\section{REFERENCIAS}

1. Levine LA, Jarrad DF. Treatment of cyclophosphamideinduced hemorrhagic cystitis with intravesical carboprost tromethamine. J Urol 1993;149(4):719-723.

2. Choong SKS, Walkden M, Kirby R. The managment of intractable haematuria . BJU Int 2000;86(9):951-959.

3. Goswami AK, Mahajan RK, Nath R, Sharma SK. How safe is $1 \%$ alum irrigation in controlling intractable vesical hemorraghe? J Urol 1993;149(2):264-267.

4. Shan BC, Albert DJ. Intravesical instillation of formalin for the managment of intractable hematuria. J Urol 1973;110 (5):519-520.

5. Fair WR. Formalin in the treatment of massive bladder hemorrhage.Techniques, results and comlications. Urology 1974;3(5):573-576.

6. Singh I, Laungani GB: Intravesical epsilon aminocaproic acid in management of intractable bladder hemorrhage. Urology 1992;40(3):227-229.
7. Liu YK, Harty JI, Steinbock GS: Treatment of radiation or cyclophosphamide induced hemorrhagic cystitis using conjugated estrogen. J Urol 1990;144(1):41-43.

8. Ribeiro RA, Freitas HC, Campos MC, Santos CC, Figueiredo FC, Brito GA et al. Tumor necrosis factor-alpha and interleukin-1beta mediate the production of nitric oxide involved in the pathogenesis of ifosfamide induced hemorrhagic cystitis in mice. J Urol 2002;167(5):22292234.

9. McIvor J, Williams G, Greswick Southcott RD, Control of severe vesical haemorrhage by therapeutic embolisation. Clin Radiol 1982;33(5):561-567.

10. Bevers RFM, Bakker Dj, Kurth KH. Hiperbaric oxygen treatment for haemorrhagic radiaton cystitis. Lancet 1995; 346:803-805.

11. Helsteim K. Treatment of bladder carcinoma by a hidrostatic pressure technique. Br J Urol 1972;14:434-450.

12. Glashan RW. A critical review of the managment of bladder neoplasia using a modified form of Helmstein's pressure therapy. Br J Urol 1975;47:57-66.

Dra. P. Serrano Frago

Lapuyade, 19 - $1^{\circ} \mathrm{A}$

50007 Zaragoza

E-mail: pserranof@comz.org

(Trabajo recibido el 23 junio de 2004) 